\title{
High Density Lipoprotein Deficiency with Xanthomas \\ A Defect in Reverse Cholesterol Transport Caused by a Point Mutation in the Apolipoprotein A-I Gene
}

\author{
Karl J. Lackner, ${ }^{*}$ Hans Dieplinger, ${ }^{*}$ Grazyna Nowicka, ${ }^{* 5}$ and Gerd Schmitz * \\ *Institut für Klinische Chemie und Laboratoriumsmedizin, Universität Regensburg, D-93042 Regensburg, Germany; \\ ${ }^{\ddagger}$ Institut für Medizinische Biologie und Humangenetik, Universität Innsbruck, A-6020 Innsbruck, Austria; \\ and ${ }^{\S}$ Laboratory of Lipoproteins, National Food and Nutrition Institute, 02-903 Warsaw, Poland
}

\begin{abstract}
A 7-yr-old girl with high density lipoprotein (HDL) deficiency and xanthomas has been identified in a Turkish kindred with repetitive consanguinity. She has severely reduced HDL-cholesterol and no apolipoprotein (apo) A-I. ApoA-II is reduced, whereas apoA-IV and apoC-III are normal. ApoB and low density lipoprotein (LDL)-cholesterol are increased. This is reflected in hypercholesterolemia. VLDL and IDL particles are low, and serum triglycerides are normal. The genetic defect could be identified as a base insertion into the third exon of the apoA-I gene. This leads to a nonsense peptide sequence beginning at amino acid 5 of the mature plasma protein and early termination of translation. The patient is homozygous for this mutation. Pedigree analysis indicated an autosomal dominant inheritance with no evidence of another genetic defect of lipoprotein metabolism in the kindred. In HDL deficiency, HDL binding to leukocytes was increased compared to normal. In the postprandial state, binding of labeled $\mathrm{HDL}_{3}$ to leukocytes is unchanged. This is in contrast to results with postprandially isolated leukocytes from controls or Tangier patients, which have a reduced binding capacity for $\mathrm{HDL}_{3}$. These results indicate that postprandial HDL precursors may compete the binding of labeled $\mathrm{HDL}_{3}$. The metabolic consequences of HDL deficiency were analyzed. There is only a small number of HDLlike particles containing apoA-II, apoA-IV, apoE, and lecithin/cholesteryl acyl transferase. The C-apolipoproteins were normal in the proband. Due to the lack of HDL they can only associate with apoB-containing particles, where they may interfere with cellular uptake. Thus, pure apoA-I deficiency leads to a complex metabolic derangement. (J. Clin. Invest. 1993. 92:2262-2273.) Key words: apolipoprotein A-I • atherosclerosis • high density lipoprotein deficiency $\bullet$ reversal cholesterol transport $\bullet$ xanthomas
\end{abstract}

\section{Introduction}

HDL are part of the plasma lipoprotein system (1). They have attracted much scientific attention in recent years, because epidemiologic data indicate an inverse correlation between HDL-

Address reprint requests to Prof. Dr. Gerd Schmitz, Institut für Klinische Chemie und Laboratoriumsmedizin, Universität Regensburg, Franz-Josef-Strauss Allee 11, D-93042 Regensburg, Germany.

Received for publication 5 January 1993 and in revised form 30 April 1993

J. Clin. Invest.

(C) The American Society for Clinical Investigation, Inc.

$0021-9738 / 93 / 11 / 2262 / 12 \$ 2.00$

Volume 92, November 1993, 2262-2273 cholesterol and the risk for premature cardiovascular disease (2-5). Furthermore, it could be shown that infusion of homologous HDL may reduce atheroma formation and induce atheroma regression in a rabbit model of atherogenesis $(6,7)$. Transgenic mice overproducing human apoA-I, the major apolipoprotein of HDL, are less susceptible to atherosclerosis (8). The mechanism of this protective effect is not known in detail.

One major function of HDL in lipid metabolism is its role as acceptor of excess cellular cholesterol which cannot be degraded by nonhepatic cells. This function is the first step in "reverse" cholesterol transport from peripheral tissues to the liver, and is currently the prime candidate for the vasoprotective effects of HDL. The mechanism, by which HDL takes up cellular cholesterol is a matter of intensive investigation. Evidence for receptor independent and receptor-mediated pathways possibly involving endocytosis or activation of second messenger systems has been found, and several models have been proposed that have been reviewed recently $(3,9,10)$. Besides HDL and its apolipoproteins the enzymes lecithin/ cholesteryl acyltransferase (LCAT) ${ }^{1}$ and hepatic lipase (HL), and cholesteryl ester transfer protein (CETP) take part in reverse cholesterol transport (3).

The two major apolipoproteins of HDL, apoA-I and apoAII, are both synthesized as preproproteins $(11,12)$. Whereas apoA-I is synthesized in the small intestine and the liver, apoAII is synthesized exclusively in the liver. Both genes have been cloned and their chromosomal localization has been determined (13-16). The apoA-I gene is found on chromosome 11 in a gene cluster with apoC-III and apoA-IV (17). The apoA-II gene is located on the long arm of chromosome $1(18,19)$.

Precursors of HDL are secreted from the intestine (20) and liver (21). Nascent HDL particles from the liver appear as discoidal particles in the plasma compartment, where they are converted to spherical HDL particles (22). The intestinally derived precursors are rich in apoA-I and apoA-IV, whereas the liver derived precursors contain predominantly apoA-I, apoAII, and apoE. Their major lipid components are phospholipids. In addition to direct synthesis, HDL precursors are formed during lipolysis of triglyceride-rich lipoproteins as so-called "surface remnants" (3). HDL precursors are transformed to larger cholesterol enriched spherical HDL particles after interaction with peripheral cells and several enzymes and proteins such as LCAT, HL, and CETP.

Several HDL deficiency syndromes have been described recently (for review see references 23-25). They may be subdivided into three major groups. One is the asynthetic or hypo-

1. Abbreviations used in this paper: CETP, cholesteryl ester transfer protein; HL, hepatic lipase; ITP, isotachophoresis; LCAT, lecithin/ cholesteryl acyl transferase; RITC, rhodamine isothiocyanate. 
synthetic type, in which there is decreased or absent production of HDL particles. The second is the hypercatabolic type, with Tangier disease as the best-known example. In this disease, there is rapid catabolism of HDL due to a defect in intracellular lipid traffic (25). In addition, there are HDL deficiencies caused by enzyme defects such as LCAT deficiency or fish-eye disease (26). Finally, there is a large group of kindreds with decreased HDL of unknown etiology (23).

In most cases HDL deficiency is not linked to the apoA-I or apoA-II genes. However, in some asynthetic cases the genetic defect could be elucidated at the DNA level (27-30). Two of these cases showed major rearrangements of the apoA-I/C-III/ A-IV gene locus on chromosome 11 leading to a complete lack of apoA-I synthesis. In one case the apoA-I and apoC-III genes were involved (27); in the other case all three genes were affected (28). In both cases the homozygous probands had severe cardiovascular disease at an early age. Two other cases have been elucidated at the gene level. One of these is caused by a point mutation in the apoA-I gene and is associated with premature cardiovascular disease (29). The other has a frameshift mutation in the carboxy-terminal region of apoA-I. Phenotypically this patient resembles LCAT deficiency. The patient has so far no signs of cardiovascular disease (30). These genetic syndromes provide additional evidence for the importance of HDL for the protection from atherosclerosis. Interestingly, the absence of apoA-II due to a splice junction mutation does not lead to hypoalphalipoproteinemia nor to cardiovascular disease (31).

In addition to HDL deficiency, there have been reports of hyperalphalipoproteinemia. In some cases further information on the genetic abnormality is available. Deficiency of CETP has been shown to lead to increased serum HDL. In this case, defective transfer of cholesteryl esters from HDL to apoB-containing particles leads to accumulation of cholesteryl esters in HDL and an increase in total HDL cholesterol and apolipoproteins $(32,33)$. Furthermore, there have been reports of hyperalphalipoproteinemia associated with overproduction of apoAI, increased activity of lipoprotein lipase, and decreased activity of hepatic triglyceride lipase (34-36).

In this report, a new case of HDL deficiency with plane xanthomas is presented, and the biochemical, genetic, and metabolic abnormalities are analyzed.

\section{Methods}

Fractionation and analysis of serum lipoproteins. Lipoproteins were isolated by sequential ultracentrifugation (model L8-70 ultracentrifuge, Beckman Instruments, Inc., Fullerton, CA) using a 50.3Ti or 70Ti rotor. Lipoprotein fractions were extensively dialyzed to remove excess $\mathrm{KBr}$. Total cholesterol, free cholesterol, triglycerides, and phospholipids were measured by enzymic methods (Boehringer Mannheim GmbH, Mannheim, FRG) (37). ApoA-I, apoA-II, and apoB were determined by a turbidimetric method (Behring, Marburg, FRG). ApoA-IV, apoC-II, apoC-III, and apoE were determined by sandwichtype ELISA. HDL-apolipoproteins were further analyzed by SDS-gel electrophoresis and Western blot as described (37).

Southern blotting. Genomic DNA was isolated from white blood cells as described (16). Restriction endonucleases were purchased from Boehringer Mannheim, and DNA was cleaved with 3-5 U of enzyme per $\mu \mathrm{g}$ of DNA under the conditions specified by the manufacturer. Electrophoresis in $0.7 \%$ agarose gels, Southern transfer, and hybridization with radiolabeled cDNA for apoA-I have been described previously ( 16). The apoA-I probe used was the PstI insert of pMDB1408. It contains exons 3 and 4 of the apoA-I gene (13).
Northern blotting. RNA was isolated from HepG2 cells or intestinal biopsies by the guanidinium-isothiocyanate procedure described by Chirgwin et al. (38). Agarose gel electrophoresis, Northern transfer and hybridization to radiolabeled cDNA were performed using standard protocols (39).

Construction of a genomic library and screening. Genomic DNA was cleaved with BamHI to completion, extracted with phenol, and ethanol precipitated. Without further size fractionation, a partial genomic library was constructed by inserting BamHI fragments into the cloning site of EMBL3 (40). The library was screened for apoA-I clones as described $(16,39)$.

DNA sequencing. Fragments from one recombinant apoA-I clone were subcloned into M13 and sequenced by the dideoxy chain terminating method (41) using a commercially available kit (Gibco-BRL, Gaitherburg, MD). PCR-fragments of exon 3 of the patient's DNA were sequenced after subcloning into pUC18.

Oligonucleotide melting. A 20 -mer oligonucleotide with the sequence of the mutant HDL-deficiency allele was synthesized and designated P1. The sequence was 5' GATGAACCCCCCCCAGAGCC 3'. It was used for oligonucleotide melting with either total genomic DNA or genomic DNA after amplification (42). P1 was 5'-end labeled to high specific activity with $\left[\gamma{ }^{32} \mathrm{P}\right]$ ATP $(7,000 \mathrm{Ci} / \mathrm{mmol}$, New England $\mathrm{Nu}$ clear, Boston, MA) using polynucleotide kinase (Boehringer Mannheim). In preliminary experiments the hybridization properties of $\mathrm{P} 1$ to cloned normal and mutant apoA-I DNA were established. Hybridization was performed after transfer of DNA to nitrocellulose in 6 $\times$ SSC, $5 \times$ Denhardt's, $0.1 \%$ SDS, $100 \mu \mathrm{g} / \mathrm{ml}$ salmon sperm DNA at $50^{\circ} \mathrm{C}$ for $16-18 \mathrm{~h}$. Filters were then washed in $6 \times \mathrm{SSC}, 0.1 \%$ SDS once briefly at room temperature, followed by $20 \mathrm{~min}$ at $55^{\circ} \mathrm{C}$, and $20 \mathrm{~min}$ at $60^{\circ} \mathrm{C}$. At $55^{\circ} \mathrm{C}$ washing temperature $\mathrm{Pl}$ binds to both the normal and the mutant apoA-I allele. At $60^{\circ} \mathrm{C}$ washing temperature it binds only to the perfectly complementary mutant apoA-I allele.

DNA amplification. A 317 bp fragment containing exon 3 of the apoA-I gene was amplified from genomic DNA using two oligonucleotides complementary to sequences in intron 2 and 3: P2, 5' CAAGCTTGGCCTTTCGGCTCA 3'; P3, 5' ACTCGGCCAGTCTGGCTTCAA $3^{\prime}$. Annealing and extension were performed at $58^{\circ} \mathrm{C}$ for $5 \mathrm{~min}$, melting at $94^{\circ} \mathrm{C}$ for $1,5 \mathrm{~min}$. The amplified DNA was blotted to nitrocellulose using a manifold (Minifold II, Schleicher \& Schuell Inc., Keene, NH) and hybridized with ${ }^{32} \mathrm{P}$-labeled $\mathrm{P} 1$ as described above.

Serum fractionation by gel filtration. Serum was fractionated by gel filtration on a Hiload 16/60 Superdex 200 prep grade column using fast protein liquid chromatography (FPLC, Pharmacia, Uppsala, Sweden) as described previously (43). $200 \mu \mathrm{l}$ of serum was applied to the column and eluted at $4^{\circ} \mathrm{C}$ with $50 \mathrm{mM}$ sodium-phosphate, $150 \mathrm{mM}$

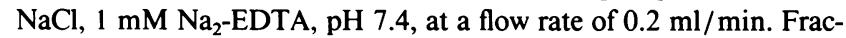
tions of $1.0 \mathrm{ml}$ were collected. The column was calibrated with human serum albumin and ultracentrifugally prepared lipoprotein fractions (VLDL, LDL, and HDL).

Analytical and preparative isotachophoresis. Analytical isotachophoresis (ITP) of lipoproteins was performed as described in detail previously $(44,45)$. Briefly, serum was preincubated with the nonpolar dye Sudanblack B ( $1 \%$ solution in ethylene glycol added in a ratio of $2: 1, \mathrm{vol} / \mathrm{vol})$ for $30 \mathrm{~min}$ at $4^{\circ} \mathrm{C}$, and mixed $(2: 1, \mathrm{vol} / \mathrm{vol})$ with defined spacers. The final concentration of each spacer was $0.2 \mathrm{mg} / \mathrm{ml}$. For separation $2 \mu \mathrm{l}$ of preincubated sample was used. The separation was carried out in the automated free flow capillary electrophoresis instrument, PACE 2000 ( Beckman Instruments, Inc., Palo Alto, CA) using a teflon capillary with a diameter of $200 \mu \mathrm{m}$. The leading electrolyte contained $5 \mathrm{mM} \mathrm{H}_{3} \mathrm{PO}_{4}, 20 \mathrm{mM}$ ammediol, $\mathrm{pH}$ 9.2. The terminating electrolyte consisted of $50 \mathrm{mM}$-aminocaproic acid, $20 \mathrm{mM}$ ammediol, $\mathrm{pH} 10$. The electrolyte solutions contained also $0.25 \%$ hydroxypropyl-methylcellulose to increase viscosity and to suppress undesired electroosmotic effects. The separated fractions were monitored at $570 \mathrm{~nm}$.

Preparative free flow isotachophoresis of lipoproteins was carried out in an Elphor VAP 22 (Bender \& Hobein, Munich, FRG) as described (44). Leading and terminating electrolytes were identical as 
described above. $1 \mathrm{ml}$ of serum was mixed with spacers (final concentration $1 \mathrm{mg} / \mathrm{ml})$ and terminating buffer $(1: 3, \mathrm{vol} / \mathrm{vol})$. The fractions collected were passed through a Sephadex G-25 PD-10 column (Pharmacia) to remove the isotachophoresis buffers and spacers for further analysis.

Determination of LCAT activity. LCAT activity in fractions from preparative ITP or Superose was measured by a proteoliposome assay as previously described (46). Proteoliposomes containing $600 \mathrm{nmol} /$ $\mathrm{ml}$ of 1-palmitoyl-2-oleyl-lecithin (Fluka, Buchs, Switzerland), 25 $\mathrm{nmol} / \mathrm{ml}$ of free cholesterol (Merck, Darmstadt, FRG), $4 \mathrm{nCi} / \mathrm{ml}$ of $\left[{ }^{3} \mathrm{H}\right.$ ] cholesterol (Amersham International, Amershaw, UK) and 100 $\mu \mathrm{g} / \mathrm{ml}$ apoA-I in Tris-buffered saline, $\mathrm{pH} 7.4$, were prepared by the cholate dialysis method. The LCAT assay was performed by preincubating $10 \mu \mathrm{l}$ of $5 \%$ fatty acid-free human serum albumin (Sigma Chemical Co., Munich), $5 \mu \mathrm{l} 20 \mathrm{mM}$ dithioerythritol (Sigma) and $70 \mu \mathrm{l}$ of proteoliposome substrate for $5 \mathrm{~min}$ at $37^{\circ} \mathrm{C}$, followed by addition of 50 $\mu \mathrm{l}$ of sample and further incubation for $10 \mathrm{~min}$ at $37^{\circ} \mathrm{C}$. The reaction was stopped and the lipids extracted by adding $1 \mathrm{ml}$ methanol/hexane ( $1: 1, \mathrm{vol} / \mathrm{vol}) .250 \mu \mathrm{l}$ of the hexane phase was applied onto small silicagel containing pasteur pipettes and eluted directly with $3 \mathrm{ml}$ hexane/diethylether (6:1, vol/ vol) into $5 \mathrm{ml}$ of scintillation liquid. Radioactivity was measured in a scintillation counter. LCAT activity was calculated from the radioactivity measured in the eluted cholesteryl esters divided by the original radioactivity.

Determination of cellular HDL-binding sites. HDL-binding sites were determined either by a flow cytometric method or by conventional analysis of ${ }^{125} \mathrm{I}$-HDL binding. Flow cytometric determination of HDL-binding sites on human leukocytes has been described in detail previously (47). Briefly, $6 \mathrm{ml}$ of EDTA blood was obtained from normal controls and patients. Leukocytes were separated by density-gradient centrifugation. They were subsequently incubated at $4^{\circ} \mathrm{C}$ for $1 \mathrm{~h}$ with $10 \mu \mathrm{g} / \mathrm{ml}$ rhodamine isothiocyanate (RITC)-conjugated $\mathrm{HDL}_{3}$. After washing, the leukocyte-bound HDL particles were determined by fluorescent flow cytometry. Specific binding was calculated by subtraction of binding in the presence of excess unlabeled $\mathrm{HDL}_{3}$ from total binding. Experiments with apoE-free ${ }^{125} \mathrm{I}$-labeled $\mathrm{HDL}_{3}$ were performed as described in detail previously (48). Instead of macrophages, granulocytes were used for these determinations. Briefly, granulocytes were isolated from whole blood by density gradient centrifugation. Subsequently, $10^{6}$ cells were incubated with ${ }^{125} \mathrm{I}_{\text {-labeled }} \mathrm{HDL}_{3}$ for $1 \mathrm{~h}$ at $4^{\circ} \mathrm{C}$. Specific binding was calculated by substracting nonspecific binding in the presence of a 25 -fold excess of unlabeled lipoprotein from total activity bound.

$L D L$ receptor assay. LDL receptors were determined on monocytes isolated from peripheral blood by a fluorescent flow cytometric method (49). Monocytes were isolated from peripheral blood as described for the HDL-binding assay. Subsequently they were kept for $\mathbf{4 8}$ $\mathrm{h}$ in MEM supplemented with $10 \%$ lipoprotein deficient serum or $10 \%$ fetal calf serum. Then they were incubated with several concentrations of a fluorescent labeled monoclonal antibody against the LDL receptor (C7). Finally, mean fluorescence was determined by flow cytometry. In addition, binding and degradation of ${ }^{125}$ I-LDL by cultured fibroblasts were determined as described by Goldstein and Brown (50).

Statistical analysis. Lipoprotein, apolipoprotein, and lipid values of controls and heterozygous members of the kindred were analyzed for significant differences with the paired $t$-test.

\section{Results}

Patient presentation. A girl of Turkish descent, now $11 \mathrm{yr}$ of age, was presented to her pediatrician because of unusual xanthomas at the age of $7 \mathrm{yr}$. Her physical examination was absolutely inconspicuous except for yellow-orange xanthomas on the flexor sides of several joints (elbow, wrist, knee). At her initial presentation, she had no corneal opacities, no enlarged tonsils, no splenomegaly, and only mild hepatomegaly on ul- trasound examination. However, during the last year she developed progressive corneal clouding detectable by slit lamp examination. Table I summarizes the lipoprotein and apolipoprotein determinations and important clinical findings of the propositus, her parents, and her sister. She has almost no cholesterol in the HDL fraction. ApoA-I was undetectable by routine assays. Gel electrophoresis after immunoprecipitation with apoA-I antibodies, and Western blotting revealed no apoA-I immunoreactive material. ApoA-II was $\sim 15 \%$ of normal. Most of the apoA-II was found in the HDL fraction and some in the lower density ranges. The only other striking abnormality in her lipoprotein profile is an elevated total cholesterol, which is due to an increase in LDL-cholesterol. This is accompanied by an increase in apoB-100. It is important to note that neither apoC-III nor apoA-IV levels were reduced.

Both her parents have low HDL-cholesterol and apoA-I levels, and a decreased ratio of HDL-cholesterol to total cholesterol. Since they are first-degree cousins, it was assumed that they are heterozygous for the same genetic defect. The younger sister also has low HDL-cholesterol and apoA-I levels and is assumed to be heterozygous. No other overt lipoprotein abnormality was detected in these three probands.

Analysis of intestinal RNA. ApoA-I is known to be synthesized in the liver and the small intestine; i.e., both tissues contain mRNA for apoA-I. A biopsy specimen from the duodenum of the HDL-deficient proband was taken after informed consent by her parents; $\sim 5-10 \mathrm{mg}$ of tissue was obtained and shock frozen. The total material was used for RNA isolation. Control intestinal RNA was isolated from pooled diagnostic biopsies. These patients were biopsied for various gastroenterologic reasons. Northern blotting showed the presence of a normal-sized mRNA for apoA-I in the child's intestinal mucosa (Fig. 1). The relative amount appears to be increased as compared to the normal controls. These experiments exclude a

Table I. Biochemical and Clinical Characteristics of the Propositus (Ö.C.), Her Sister (D.C.), Father (K.C.), and Mother (N.C.)

\begin{tabular}{lcccc}
\hline & $\begin{array}{c}\text { Ö.C. } \\
(\mathrm{V}-1) \\
\mathrm{F}, 11 \mathrm{yr}\end{array}$ & $\begin{array}{c}\text { D.C. } \\
(\mathrm{V}-2)\end{array}$ & $\begin{array}{c}\mathrm{K}, 9 \mathrm{yr} . \\
(\mathrm{IV}-15) \\
\mathrm{M}, 30 \mathrm{yr}\end{array}$ & $\begin{array}{c}\mathrm{N} . \mathrm{C} . \\
(\mathrm{IV}-6) \\
\mathrm{F}, 31 \mathrm{yr}\end{array}$ \\
\hline Triglycerides $(m g / d l)$ & 107 & 133 & 86 & 53 \\
Cholesterol $(m g / d l)$ & 222 & 160 & 138 & 192 \\
VLDL-cholesterol $(m g / d l)$ & 22 & 27 & 17 & 11 \\
LDL-cholesterol $(m g / d l)$ & 198 & 95 & 92 & 143 \\
HDL-cholesterol $(m g / d l)$ & 2 & 38 & 29 & 38 \\
ApoA-I $(m g / d l)$ & 0 & 81 & 85 & 82 \\
ApoA-II $(m g / d l)$ & 5 & 35 & 40 & 39 \\
ApoA-IV $(m g / d l)$ & 16.2 & $\mathrm{n} . \mathrm{d}$. & $\mathrm{n} . \mathrm{d}$. & $\mathrm{n} . \mathrm{d}$. \\
ApoB $(m g / d l)$ & 125 & 79 & 64 & 73 \\
ApoC-III $(m g / d l)$ & 8.8 & 9.4 & 11.1 & 10.5 \\
ApoE $(m g / d l)$ & 4.9 & 4.0 & 5.2 & 5.4 \\
ApoE phenotype & $\epsilon 3 / 3$ & $\epsilon 3 / 3$ & $\epsilon 3 / 3$ & $\epsilon 3 / 4$ \\
ApoA-I haplotype & $\alpha \mathrm{I} 1 / 1$ & $\alpha \mathrm{I} 1 / 9$ & $\alpha \mathrm{I} 1 / 9$ & $\alpha \mathrm{I} 1 / 1$ \\
Xanthomas & ++ & 0 & 0 & 0 \\
Corneal clouding & + & 0 & 0 & 0 \\
Splenomegaly & 0 & 0 & 0 & 0 \\
Hepatomegaly & $(+)$ & 0 & 0 & 0 \\
& & & & \\
\hline
\end{tabular}

The numbers in parentheses refer to the position in the kindred. 


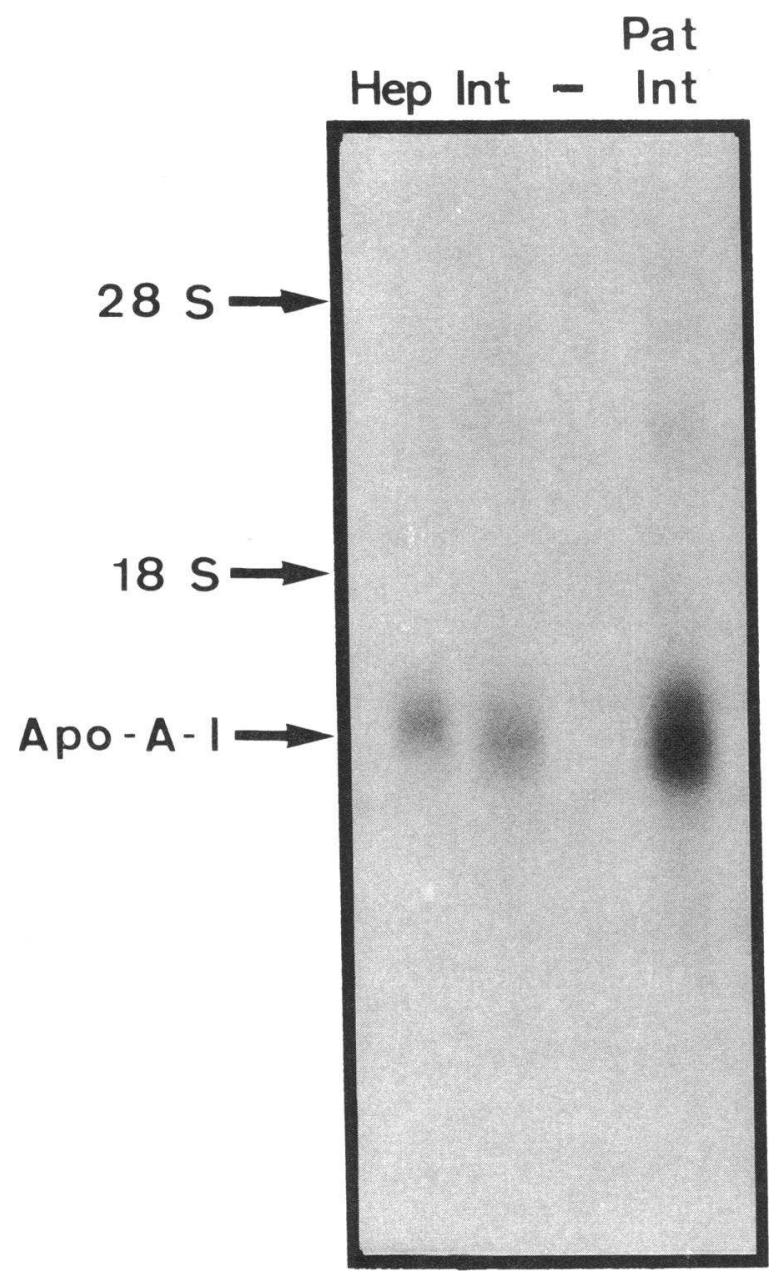

Figure 1. Northern blot with an apoA-I cDNA of total RNA isolated from HepG2 cells (Hep), control intestinal biopsies (Int), and the HDL-deficient proband (Pat Int). In each lane $\sim 5 \mu \mathrm{g}$ of RNA were loaded. The amount of RNA in each lane was similar as judged from the ethidium bromide-stained gel before Northern transfer. The intestinal biopsy of the patient contains an apoA-I message of normal size. The amount appears to be increased. However, no attempt at precise quantitation has been made, because it is not possible to estimate the amount of mucosal vs. stromal cells in the biopsy, which determines the relative amount of apoA-I message in the RNA sample.

promoter or splicing defect of the apoA-I gene as the cause for HDL deficiency in this case.

Haplotype analysis. Haplotype analysis was performed with four restriction enzymes (PstI, SacI, TaqI, and MspI) which have relatively common two-allele RFLPs at the apoA-I locus (51). A total of 16 hypothetical haplotypes may be expected. Only four of them, which were designated $\alpha \mathrm{I}-1, \alpha \mathrm{I}-3$, $\alpha \mathrm{I}-6$, and $\alpha \mathrm{I}-9$ were found in the family. There was cosegregation of low HDL-cholesterol and apoA-I with allele $\alpha \mathrm{I}-1$. However, since this is the most common haplotype in a caucasian population as well as in the family, no significant lod-score could be calculated.

Cloning and sequencing. The father of the proband had been shown to be heterozygous for a common PstI RFLP with a 2.2- and a 3.3-kb allele (haplotype $\alpha \mathrm{I} 1 / 9$ ). The propositus, his daughter is homozygous for the $2.2-\mathrm{kb}$ allele. Thus, the allele passed to his daughter can be identified readily. Because the amount of DNA available from the proband was limited, the father's DNA was used to construct a partial genomic library in the $\lambda$-phage EMBL3. This vector can accommodate DNA fragments from 9 to $16 \mathrm{~kb}$. The apoA-I gene is contained within a 12-kb BamHI fragment. Thus, insertion of BamHI fragments of genomic DNA into EMBL3 results in a genomic library enriched in apoA-I clones. Four genomic clones out of 150,000 screened gave positive hybridization signals with the apoA-I cDNA-probe. Restriction fragment analysis of these clones showed that they all contained the expected $12-\mathrm{kb}$ BamHI fragment. Three out of four contained a 2.2-kb PstI fragment, one contained a 3.3-kb PstI fragment. One of the clones with the 2.2-kb PstI fragment, designated $\lambda$ apoA-I-7, was used for further analysis and sequencing.

Fig. 2, $A$ and $B$, shows sequencing gels of the third exon of the apoA-I gene. There is an insertion of a cytosine base into the codon of amino acid 5 of the mature plasma apoA-I. In Fig. $3 A$ the nucleic acid sequence of exon 3 is illustrated. The inserted cytosine is marked by an arrow. Fig. $3 B$ shows the hypothetical translation product of the mutant apoA-I gene. The leader sequence (amino acids -24 to -7 ), the propeptide (amino acids -6 to -1 ) and the first 4 amino acids are identical to normal apoA-I. Beginning with amino acid 5, a nonsense peptide is encoded that terminates at amino acid 33.

Four more single-base substitutions within the introns and the $3^{\prime}$ untranslated region were detected (data not shown), when compared to a published sequence (14).

Oligonucleotide melting. To directly prove that the eighth cytosine base is in fact the cause for apoA-I deficiency, an oligonucleotide with the mutant sequence (P1) was synthesized. In preliminary experiments hybridization conditions were established such that P1 either bound to both the normal and mutant allele or that P1 bound exclusively to the mutant allele (see Methods). When DNA of the proband's father was cleaved with PstI and hybridized with P1 at low stringency both the 3.3-
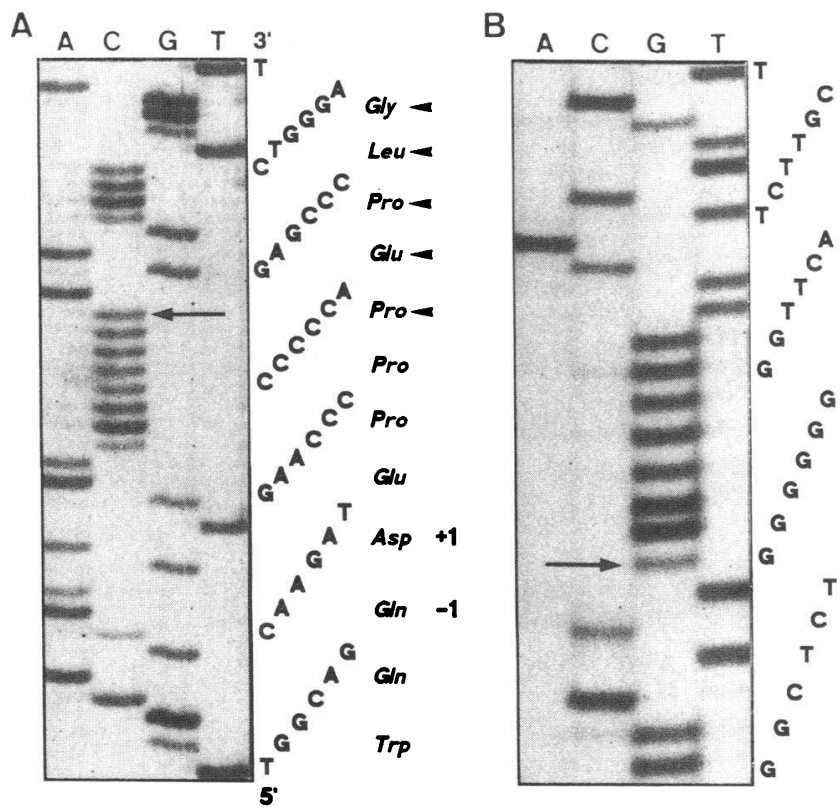

Figure 2. Sequencing reactions of the $(A)$ coding and $(B)$ noncoding strand of the mutated region in exon 3 . The nucleic acid sequence and encoded amino acid sequence are indicated. The inserted base is marked by an arrow. The cytosine insertion leads to a sequence of eight cytosine residues instead of seven as in the wild-type sequence. 


\section{A}

IVS II GGAGCCAGGCTCGGCATTTCTGGCAGCAAGATGAACCCCCCCC A GAGCCCCTGGGATCGAGTGAAGGACCTGGCCACTGTGTACGTGGATGTGC CAAAGACAGCGGCAGAGACTATGTGTCCCAGTTTGAAGGCTCCGCCTTGGG AAAACAGCTAAA IVS III

\section{B}

Met Lys Ala Ala Val Leu Thr Leu Ala Val Leu Phe Leu Thr Gly Ser Gin Ala $\begin{array}{llll}-6 & -1 & 1 & 12\end{array}$ Arg His Phe Trp Gin Gin Asp Glu Pro Pro Pro Glu Pro Leu Gly Ser Ser Glu $13 \longrightarrow 30$ Gly Pro Gly His Cys Val Arg Gly Cys Ala Gin Arg Gin Arg Gin Arg Leu Cys $31 \quad 33$ Val Pro Va

Figure 3. ( $A$ ) Sequence of exon 3 of the mutant apoA-I gene. The inserted base is marked by an arrow. $(B)$ Hypothetical translation product of the mutant apoA-I gene. It differs from the wild-type from position 5 of the mature protein (arrow).

and the 2.2-kb apoA-I bands were seen. At higher stringency only the $2.2-\mathrm{kb}$ band hybridized to $\mathrm{P} 1$. This experiment provides evidence that the $2.2-\mathrm{kb}$ PstI fragment contains the cytosine insertion. It also proves that the insertion is on the same allele which the HDL-deficient proband inherited from her father.

Since the background of oligonucleotide melting on total genomic DNA was substantial, we decided to analyze the DNA of the other family members after amplification of exon 3 of the apoA-I gene. A 317 bp fragment containing exon 3 was amplified using P2 and P3 as primers. The amplified DNA was applied to a nitrocellulose filter and hybridized to P1 under stringent conditions which permit only hybridization to the mutant allele (Fig. 4). The amplified DNA from 15 members of the family (including the propositus and her parents) hybrid-

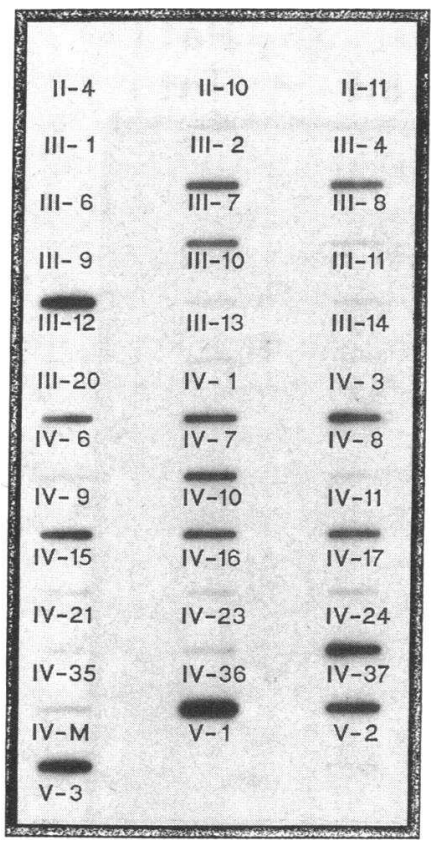

Figure 4. Slot blot of amplified exon 3-DNA from the kindred. The numbers refer to the position in the kindred. The DNA was hybridized to oligonucleotide $\mathrm{P} 1$ at $60^{\circ}$ so that $\mathrm{P} 1$ binds only to the mutant DNA sequence. The presence of a DNA band indicates the presence of the mutant apoA-I allele. One individual (II-13) could not be analyzed by this method, since no more DNA was available. IV-M is identical to III-25 who married IV-10. This person was initially included in generation IV. Later, it became clear that this was another consanguinous marriage.

ized to P1 under these conditions, indicating the presence of at least one mutant allele.

The "wild type" oligonucleotide was not suitable for oligonucleotide melting even with cloned DNA (data not shown). Therefore, amplified DNA from exon 3 of the patient was sequenced after subcloning into pUC18 in order to prove that she is homozygous for the cytosine insertion. When eleven independent clones were sequenced, all of them contained the additional cytosine base (Fig. 5). This constellation has a probability of 1:2,048 in a heterozygous individual and is taken as evidence for homozygosity.

The family members were categorized as heterozygotes when the mutant allele was present and serum apoA-I was de-

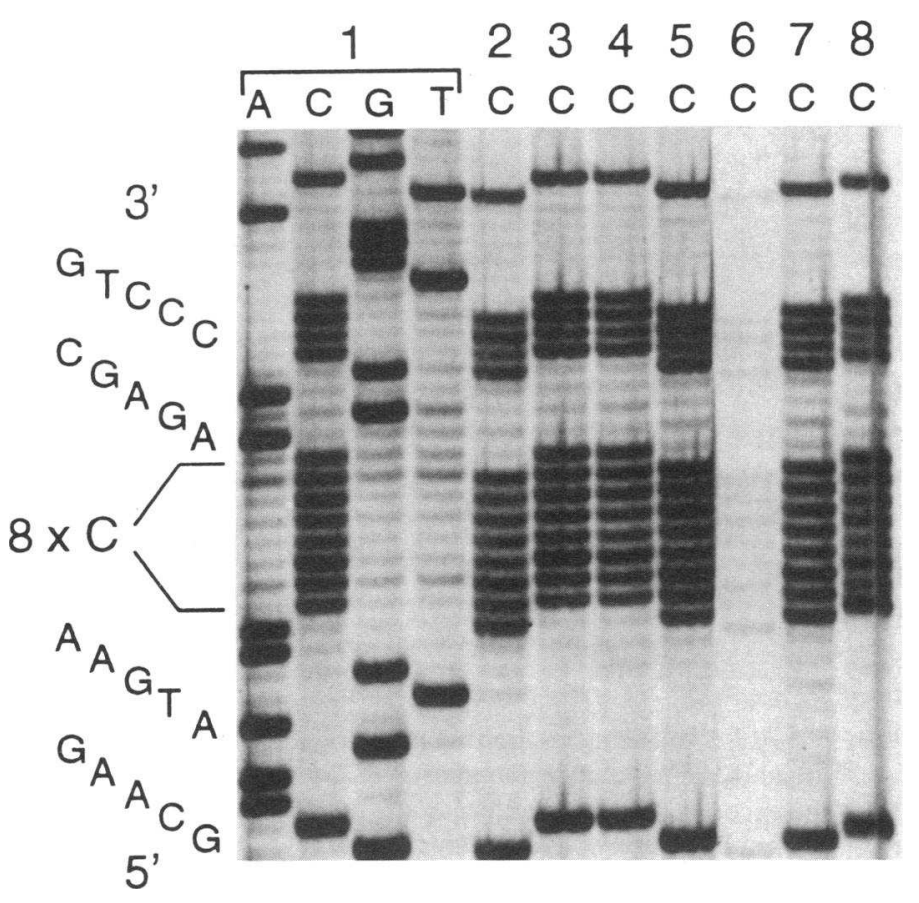

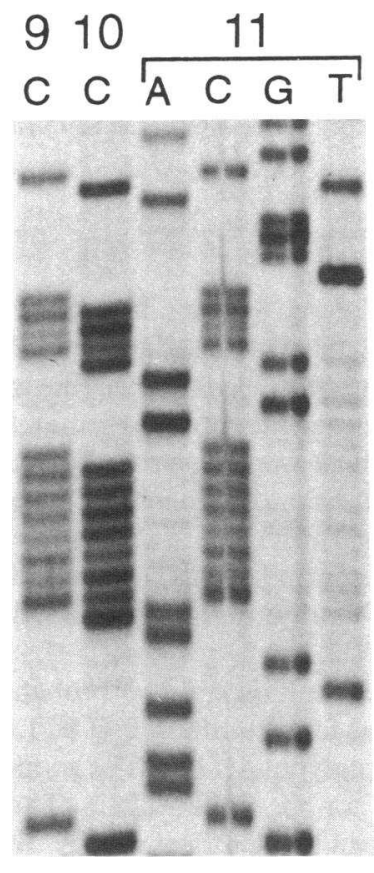

Figure 5. Sequence analysis of PCR-derived clones. Exon 3 of the patient's DNA was amplified and inserted by blunt end ligation into pUC18. 11 independent clones were sequenced. Lane $l$ contains the $\mathrm{A}, \mathrm{C}, \mathrm{G}$, and $T$ sequencing reactions of one clone. Lanes 2-8 show the $C$ reaction of 7 other clones which were inserted into pUC18 in the plus direction. The clones differ in length by up to two bases probably due to the blunt end cloning procedure. Lanes 9 and 10 show the $\mathrm{C}$ reaction from two clones inserted in the minus direction, and lane 11 the $\mathrm{A}$, $\mathrm{C}, \mathrm{G}$, and $\mathrm{T}$ reactions of one clone also inserted in the minus direction. It is obvious that all clones have the stretch of eight cytosines, indicating homozygosity for the cytosine insertion. 
tectable. Probands not having the mutant allele were defined as "normal". Table II summarizes the lipid metabolism data of these two groups. The most significant difference between the heterozygotes and the normals is reflected in their apoA-I levels. Heterozygotes have also lower HDL-cholesterol, phosphatidylcholine, and sphingomyelin. ApoA-II is only slightly reduced in the heterozygotes. This difference does not reach statistical significance.

No family member with HDL-cholesterol $>40 \mathrm{mg} / \mathrm{dl}$ or apoA-I $>100 \mathrm{mg} / \mathrm{dl}$ has the cytosine insertion, whereas all but one of the others have the mutant allele. The homozygote proband has no apoA-I and almost no HDL-cholesterol. This is evidence that the mutation represents an autosomal dominant trait with a gene dosage effect. One individual with an HDLcholesterol of $26 \mathrm{mg} / \mathrm{dl}$ and an apoA-I of $93 \mathrm{mg} / \mathrm{dl}$, does not have the cytosine insertion according to oligonucleotide melting. His haplotype is $\alpha \mathrm{I}-6 / 9$. Since the cytosine insertion cosegregates with allele $\alpha \mathrm{I}-1$, his cause for low HDL-cholesterol and apoA-I must be different from the apoA-I mutation described here.

Fig. 6 represents a pedigree of the family. Family members heterozygous for the cytosine insertion are shown with halffilled symbols. The homozygous proband is shown by the filled circle.

Analysis of $L D L$ receptor activity. Hypercholesterolemia in the proband is most likely not caused by an LDL receptor defect, since both her parents have normal LDL-cholesterol. To ascertain this assumption, LDL receptors were determined by a fluorescence flow cytometric method in monocytes and by conventional binding of iodine labeled LDL to fibroblasts. As

Table II. Lipid Parameters of the Kindred

\begin{tabular}{lccc}
\hline & $\begin{array}{c}\text { Normal: } \\
\text { mean }(\mathrm{SD}) ; \\
n=22 \\
(\mathrm{M} / \mathrm{F}=12 / 10)\end{array}$ & $\begin{array}{c}\text { Heterozygote: } \\
\text { mean }(\mathrm{SD}) ; \\
(\mathrm{M} / \mathrm{F}=8 / 6)\end{array}$ & Significance \\
\hline Age & $42.1(19.8)$ & $28.5(15.4)$ & $P<0.025$ \\
Triglycerides $(m g / d l)$ & $73.3(32.0)$ & $95.9(46.5)$ & n.s. \\
Cholesterol $(m g / d l)$ & $190.7(39.2)$ & $174.4(44.7)$ & n.s. \\
VLDL-cholesterol $(m g / d l)$ & $14.7(6.4)$ & $19.2(9.3)$ & n.s. \\
LDL-cholesterol $(m g / d l)$ & $133.3(37.5)$ & $128.1(45.8)$ & n.s. \\
HDL-cholesterol $(m g / d l)$ & $42.8(10.2)$ & $27.1(6.5)$ & $P<0.001$ \\
ApoA-I $(m g / d l)$ & $124.5(18.5)$ & $78.1(9.5)$ & $P<0.001$ \\
ApoA-II $(m g / d l)$ & $34.0(6.5)$ & $30.6(5.9)$ & $P<0.1$ \\
ApoB $(m g / d l)$ & $79.5(22.2)$ & $82.8(27.6)$ & n.s. \\
ApoE $(m g / d l)$ & $5.1(1.6)$ & $5.7(1.5)$ & n.s. \\
Phosphatidylcholine $(m g / d l)$ & $28.7(5.9)$ & $21.8(3.0)$ & $P<0.025$ \\
Sphingomyelin $(m g / d l)$ & $10.1(2.2)$ & $7.2(0.8)$ & $P<0.025$ \\
PC/SPM ratio & $2.9(0.3)$ & $3.0(0.2)$ & n.s. \\
& & & \\
\hline
\end{tabular}

"Normals" are defined as not having the mutant apoA-I allele according to oligonucleotide melting. "Heterozygotes" are defined as having the mutant allele. The homozygous proband is not included in this table. There is a significant age difference between the normals and the heterozygotes. This significance is lost if two children (V2 and V3) are not considered. On the other hand the other significant differences are not affected. The heterozygotes have significantly lower apoA-I and HDL-cholesterol levels than the normals. In addition, they have lower serum phophatidylcholine and sphingomyelin levels. ApoA-II levels appear to be lower, but this difference does not reach statistical significance. expected, there was no difference in LDL bound to monocytes or fibroblasts between cells from normal controls, the proband and her parents (data not shown). In addition LDL degradation was the same as in normal controls. Thus, the increased LDL cholesterol of the proband is not caused by a LDL receptor defect.

Analysis of HDL-binding sites. HDL binding to granulocytes or monocytes from the HDL deficient proband, her parents and normal controls was assessed by a fluorescence based flow cytometric method and by binding of ${ }^{125} \mathrm{I}-\mathrm{HDL}$. These studies indicate that maximal binding is increased by $\sim 25 \%$ in the HDL deficient proband with unchanged $K_{\mathrm{d}}$. This is similar to Tangier disease and indicates upregulation of cellular HDLbinding sites in HDL deficiency (Fig. 7).

Since we had observed a postprandial decrease of RITCHDL binding to Tangier and normal leukocytes, a similar experiment was performed in HDL deficiency with xanthomas. First, postprandial changes of apolipoprotein levels in plasma were analyzed. Data from other laboratories indicate that serum apoA-IV increases, whereas apoA-I and apoA-II do not change significantly. HDL apoA-I declines $(52,53)$. After a standard fat meal (1,600 kcal, $70 \%$ fat $)$ there was a small increase in plasma apoA-I and a decrease of HDL apoA-I in normal controls. In contrast, in a Tangier patient there was an almost threefold increase in plasma apoA-I (from 5.8 to 14.6 $\mathrm{mg} / \mathrm{dl} 5 \mathrm{~h}$ postprandial). No apoA-I is detectable in the proband's fasting and postprandial plasma. Plasma apoA-IV increases in controls, Tangier patients and the proband similarly (from $\sim 16$ to $25 \mathrm{mg} / \mathrm{dl}$ ). ApoA-II increases in Tangier patients (from 9.5 to $23 \mathrm{mg} / \mathrm{dl}$ ), whereas there is no major change in controls and the proband. The increase in apoA-I in Tangier patients is most likely related to apoA-I secreted with chylomicrons. Thus, there is a substantial increase in apoA-Icontaining particles postprandially in Tangier disease which may bind to cellular receptors.

When HDL binding to leukocytes isolated either in the fasting or postprandial state was analyzed, a decrease in binding of normal ${ }^{125} \mathrm{I}-\mathrm{HDL}$ and RITC-HDL to postprandial Tangier leukocytes was observed. In HDL deficiency with xanthomas no effect of the postprandial state on HDL-binding was observed (Figs. 7 and 8 ). Since Tangier patients secrete normal chylomicrons, this was interpreted as competition of postprandial apoA-I containing particles with labeled $\mathrm{HDL}_{3}$ for cellular HDL-binding sites.

Analysis of lipoproteins by gel filtration. ApoA-IV concentration in the homozygous proband was shown to be normal. However, the distribution of apoA-IV among lipoproteins separated by gel filtration differed from normal subjects. There was substantially less apoA-IV lipoprotein associated in the HDLdeficient serum ( $13 \%$ vs. $25 \%$ ). Also the apoA-IV containing particles were smaller indicating a higher density (Fig. $9 \mathrm{~A}$ ).

Distribution of LCAT activity was not substantially different between normal serum and serum of the HDL-deficient proband. However, it appeared that more activity was not associated ( $51 \%$ vs. $44 \%$ ) with lipoprotein particles (Fig. 9 B).

Analytical and preparative isotachophoresis. To gain further insight into lipoprotein metabolism in HDL deficiency with xanthomas, lipoproteins of the HDL deficient proband were analyzed by analytical and preparative ITP. By analytical ITP HDL may be separated into six major peaks (44). Peaks 1 and 2 are rich in apoA-I, phosphatidylcholine, and triglycerides. Peak 3, which contains most of the HDL protein, is 


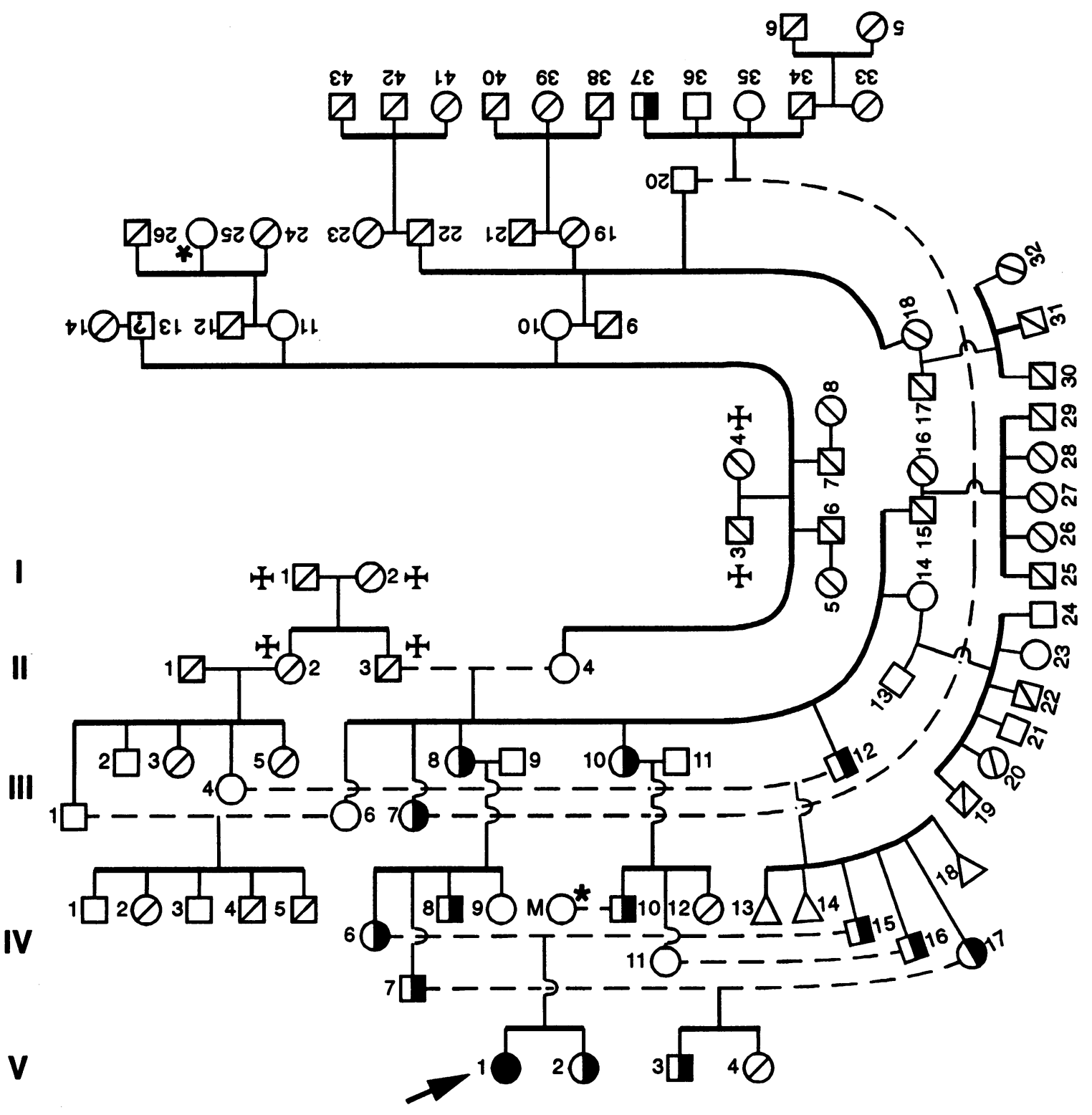

Figure 6. Pedigree of the HDL deficiency kindred. Half-filled symbols indicate heterozygotes according to the oligonucleotide melting data. A slash indicates that an individual was not available for blood sampling. Triangles indicate stillbirths. Consanguinous marriages are marked by a dashed line. The homozygous proband $(\mathrm{V}-1)$ is indicated by an arrow. The asterisk for individual IV-M indicates that this women is identical to III-25. Initially it was not known that she was the daughter of II-11 and II-12. A total of 37 individuals from four generations could be analyzed.

enriched in apoA-II and apoE. Peaks 4-6 contain most of apoA-IV $(\sim 69 \%)$ and most of LCAT $(\sim 75 \%)$ in HDL (44). The apoB-containing particles are separated into eight fractions (45). Peak 7 represents chylomicrons, peaks 8-10 represent VLDL and remnant particles, peaks 11-14 represent LDL particles. When analytical ITP of serum from the patient with HDL deficiency with xanthomas is compared to serum from normal and Tangier disease (Fig. 10), it is obvious that there is almost complete absence of fractions 1 and 2. Fraction 3 is significantly lower than in normal, but there is some material present. Compared to Tangier disease, peaks 1 and 2 appear to be even smaller, whereas there is more lipoprotein in peak 5. The other relevant finding is the small amount of lipoprotein particles in the remnant fractions (peaks 8-10) in HDL deficiency with xanthomas. On the other hand there is an increase in the LDL fractions, particularly peaks 13 and 14 . This is completely different from Tangier disease, where triglyceride rich particles accumulate, but LDL is reduced. This is probably related to decreased lipoprotein lipase activity in Tangier disease (25).

Analytical ITP does not permit quantitation of apolipoproteins and other components within the single fractions. Thus, preparative ITP was performed. There were only traces of apolipoproteins and lipids in the area corresponding to normal fast-migrating HDL (peaks 1 and 2). In the intermediate migrating HDL (peak 3) a small amount of apoA-II, phospholipids (7.2\% of total serum phospholipids) and cholesterol ( $0.6 \%$ of total cholesterol) was found (Table III). This subfraction also contained apoA-IV (Table IV). The slow migrating HDL subpopulations contained most of the HDL associated apoA-IV, apoA-II, apoE and a small amount of phospholipids ( $3.7 \%$ of total) and cholesterol ( $0.5 \%$ of total cholesterol). This 


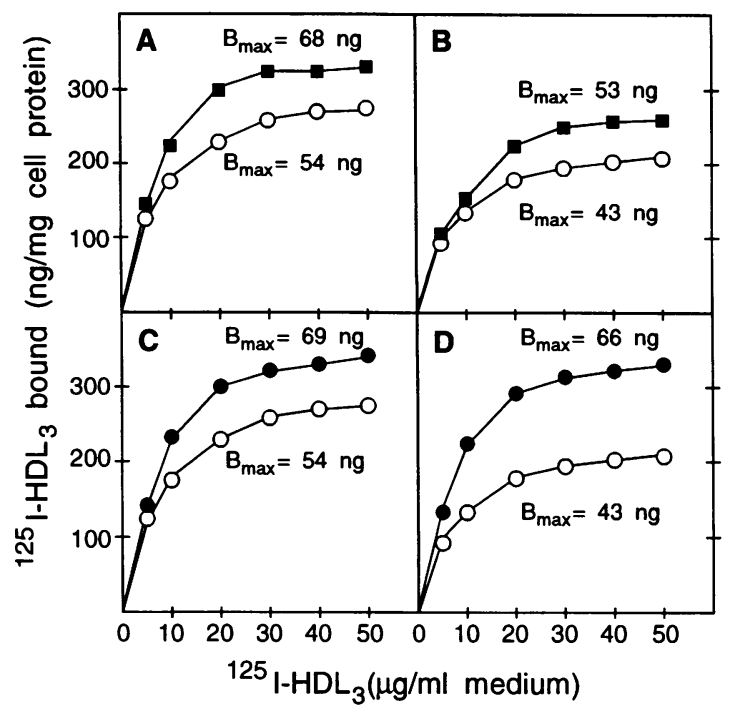

Figure 7. Binding of apoE-free ${ }^{125} \mathrm{I}_{-} \mathrm{HDL}_{3}$ to granulocytes from control probands, a Tangier patient and the HDL deficient proband. Specific binding defined as total binding minus binding in the presence of a 25 -fold excess of unlabeled $\mathrm{HDL}_{3}$ is shown. There is an increase in the maximal binding of ${ }^{125} \mathrm{I}-\mathrm{HDL}_{3}$ to the cells of the Tangier patient $(A)$ and the HDL-deficient proband $(C)$ compared to normal. Cells isolated $4 \mathrm{~h}$ postprandially from controls and a Tangier patient bind less $\mathrm{HDL}_{3}$ than fasting cells $(B)$. In HDL deficiency, there is no change in postprandial $\mathrm{HDL}_{3}$ binding $(D)$.

is different from normal, where apoA-II and apoE are found predominantly in intermediate migrating HDL (44). This indicates that the composition of these particles differs between normal controls and HDL deficiency with xanthomas. LCAT activity is found in both intermediate and slow-migrating HDL.

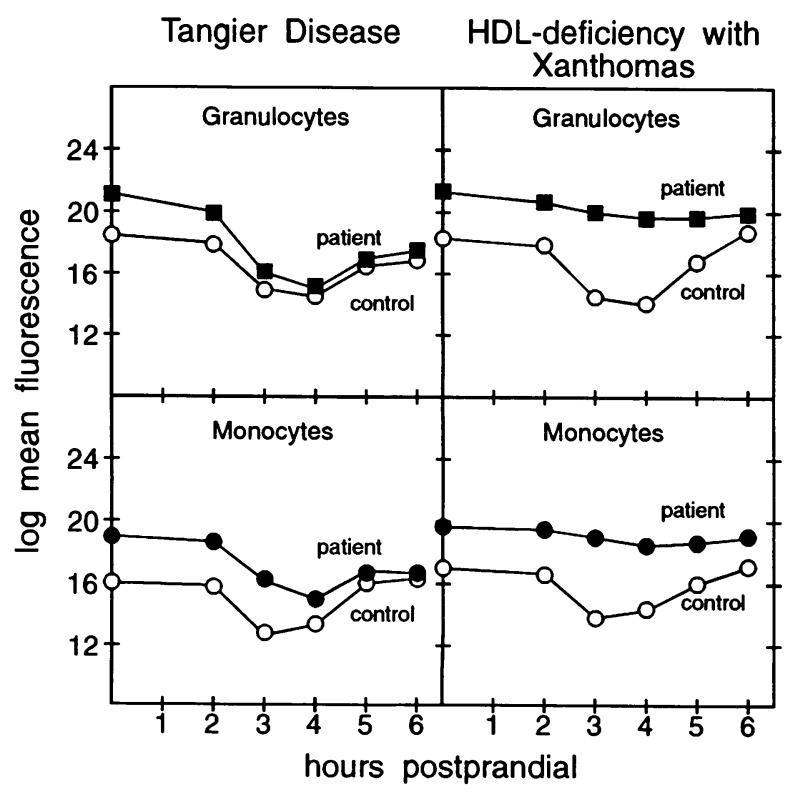

Figure 8. Binding of RITC-HDL ${ }_{3}$ to leukocytes from normal probands, a Tangier patient, and the HDL-deficient proband. In both monocytes and granulocytes of normal and Tangier disease there is a decrease in $\mathrm{HDL}_{3}$ binding. The decrease is maximal after 3 and $4 \mathrm{~h}$. In the HDL-deficient proband there is only a very slight decrease in binding of RITC-HDL ${ }_{3}$ to postprandially isolated leukocytes.

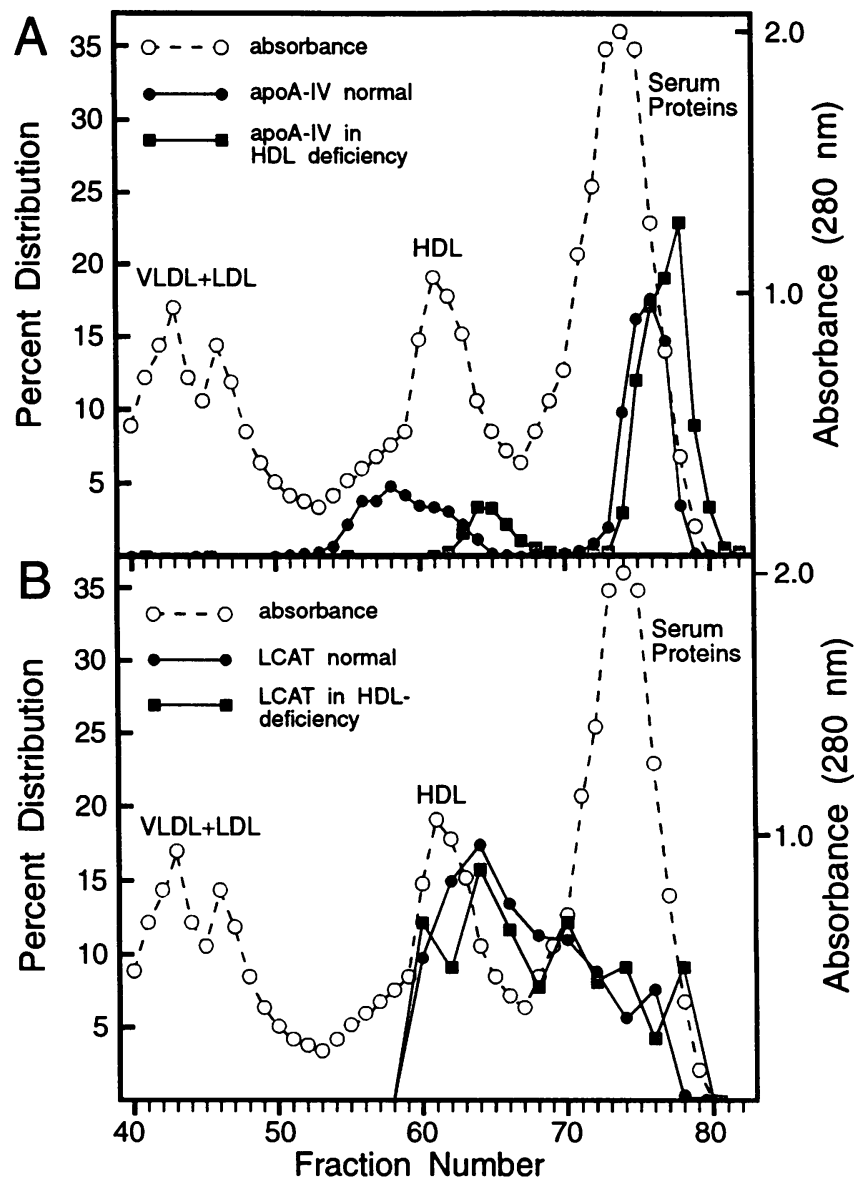

Figure 9. Gel filtration elution profiles of apoA-IV $(A)$ and LCAT $(B)$ from normal and HDL deficiency serum. Lipoprotein associated ApoA-IV in HDL deficiency is only half that found in normal (13\% vs. $25 \%$ ). In addition, it elutes later, i.e., as a smaller particle. LCAT also appears to be less lipoprotein associated and elutes with smaller particles. However, this is not as striking as with apoA-IV.

These data indicate that the residual particles found in HDL in the proband's plasma are most likely $(a)$ apoE/apoAII particles within the slow-migrating HDL population and $(b)$ apoA-IV/LCAT particles within the intermediate and slowmigrating HDL population. However, due to the complete absence of apoA-I, all HDL populations are severely reduced. The shift of HDL protein constituents into other lipoprotein fractions or into the non-lipoprotein serum protein pool may have important metabolic consequences.

\section{Discussion}

The genetic defect leading to HDL deficiency with xanthomas in a Turkish kindred has been analyzed. Cloning and sequencing of the mutant apoA-I allele revealed that there is a cytosine insertion in the third exon of the apoA-I gene. This insertion leads to a frameshift so that the open reading frame codes for a hypothetical translation product which is only 57 amino acids long. The propositus could be shown to be homozygous for the mutation.

There were four more base substitutions compared to the published gene sequence found. All these differences were located in introns or in the $3^{\prime}$ untranslated region. Thus, they 


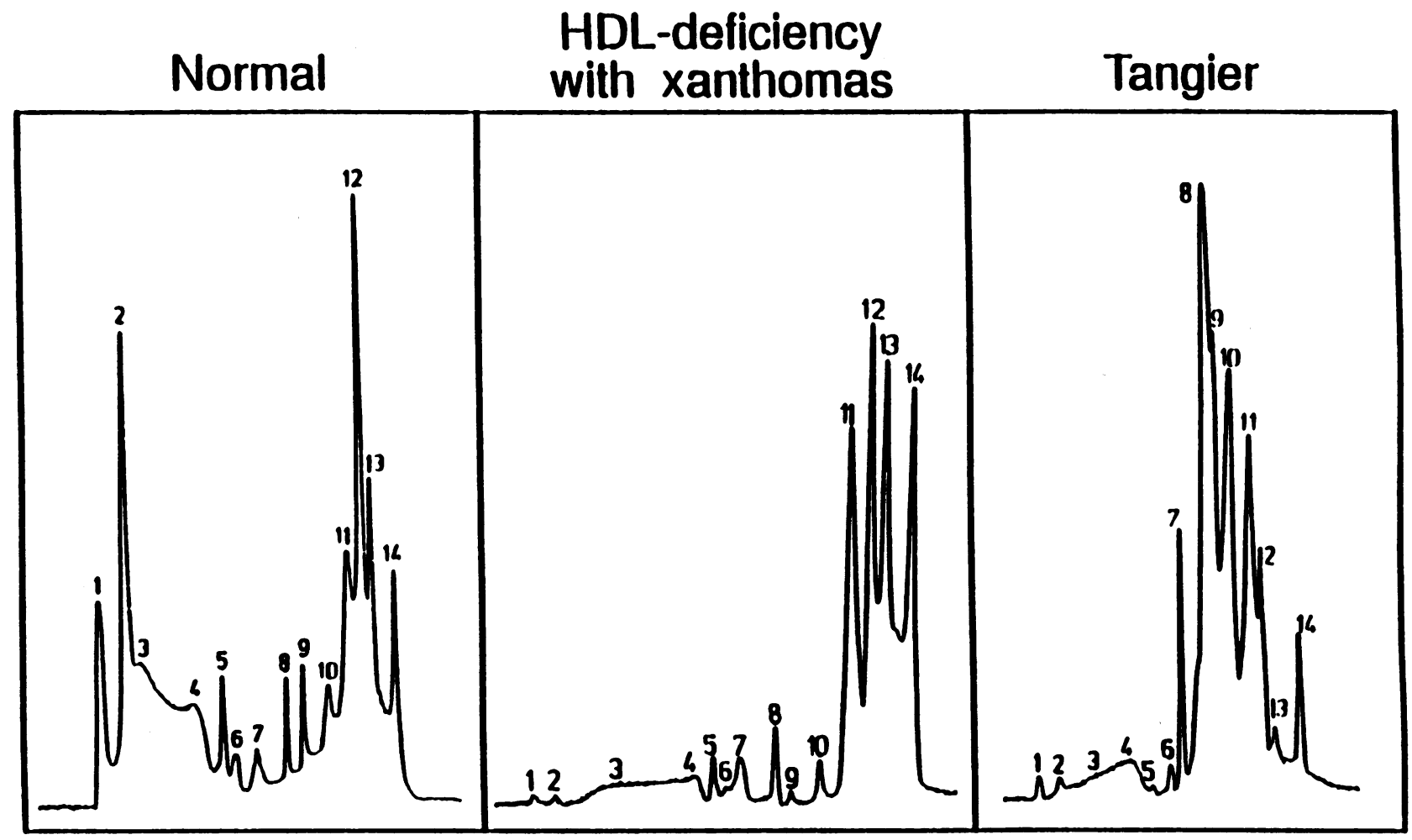

Figure 10. ITP patterns from normal, HDL deficiency with xanthomas, and Tangier disease. Peaks 1-6 correspond to HDL subpopulations, peak 7 to chylomicron-derived particles, peaks 8-10 to VLDL and IDL subpopulations, and peaks 11-14 to LDL subpopulations. It is obvious that all HDL subpopulations are severely reduced in HDL deficiency with xanthomas and Tangier disease. The remaining material is found in peaks 3-5. In normal plasma these peaks contain particles enriched in apoE and apoA-II as well as particles enriched in apoA-IV and LCAT. In contrast to Tangier in HDL deficiency with xanthomas, most apoB-containing particles are found in the LDL range.

cannot influence the primary structure of the translation product. Interference with expression or splicing of the apoA-I gene is unlikely for two reasons. First, the Northern blot experiment showed that the apoA-I mRNA of the HDL-deficient proband is of normal size. And secondly, the presence of reasonable amounts of apoA-I message also precludes a defect in apoA-I gene expression as the cause for apoA-I deficiency. In fact, the number of differences observed is less than that between two previously published sequences $(14,54)$, so that we assume that this represents the normal variability of the apoA-I gene locus.

Pedigree analysis showed that the cytosine insertion cosegregates with low HDL in this family. All individuals within the pedigree who were heterozygous for the cytosine insertion had apoA-I levels $<100 \mathrm{mg} / \mathrm{dl}$ and HDL-cholesterol $<40 \mathrm{mg} / \mathrm{dl}$.

Table III. Percent Distribution of Total Serum Protein and Cholesterol in HDL Subfractions of the HDL-deficient Proband

\begin{tabular}{lccc}
\hline & $\begin{array}{c}\text { Fast-migrating } \\
\text { HDL }\end{array}$ & $\begin{array}{c}\text { Intermediate-migrating } \\
\text { HDL }\end{array}$ & $\begin{array}{c}\text { Slow-migrating } \\
\text { HDL }\end{array}$ \\
\hline ApoA-II (\%) & $0.6(23.0)$ & $15.8(31.6)$ & $57.6(26.4)$ \\
ApoE (\%) & traces (traces) & traces (traces) & $17.6(13.3)$ \\
Cholesterol (\%) & traces (6.5) & $0.6(12.6)$ & $0.5(5.9)$ \\
\hline
\end{tabular}

The majority of serum apoA-II is found in slow migrating HDL. In addition, approximately one sixth of serum apoE is found in slow migrating HDL. Numbers in parentheses are from a normal control.
The homozygous proband had no apoA-I and only trace amounts of HDL cholesterol. This is evidence that hypoalphalipoproteinemia is inherited as an autosomal dominant trait in this family.

One member of the pedigree (III-11) had an apoA-I of 93 $\mathrm{mg} / \mathrm{dl}$ and an HDL-cholesterol of $26 \mathrm{mg} / \mathrm{dl}$. This individual married into the family, has a different apoA-I haplotype as expected for a carrier of the mutation, and does not have the cytosine insertion as shown by oligonucleotide melting. His cause for low HDL and apoA-I is not known. However, it is clear that it is not the same as found in the other individuals. None of his apoA-I alleles appears to be linked to low HDL in his offspring.

Several HDL-deficiency syndromes have been described. They may be grouped into different categories. The case de-

Table IV. Percent Distribution of ApoA-IV and LCAT in HDL Fractions of the HDL-deficient Proband

\begin{tabular}{lccc}
\hline & $\begin{array}{c}\text { Fast-migrating } \\
\text { HDL }\end{array}$ & $\begin{array}{c}\text { Intermediate-migrating } \\
\text { HDL }\end{array}$ & $\begin{array}{c}\text { Slow-migrating } \\
\text { HDL }\end{array}$ \\
\hline ApoA-IV (\%) & $4.5(15.6)$ & $13.8(15.6)$ & $81.7(68.8)$ \\
LCAT (\%) & $11.6(13.1)$ & $35.2(11.5)$ & $53.2(75.4)$ \\
\hline
\end{tabular}

Both proteins are found predominantly in slow-migrating HDL. Since a large percentage of both proteins is not lipoprotein associated, only the relative distribution within HDL is given. Numbers in parentheses represent the distribution in normal HDL (see reference 44). 
scribed here is caused by the inability to synthesize apoA-I, the major apolipoprotein of HDL. There have been more "asynthetic" cases described in the literature. They differ from this case in several respects. In two cases the apoC-III gene or both the apoC-III and the apoA-IV genes are affected in addition to the apoA-I gene $(27,28)$.

There are important metabolic differences to apoA-I/ apoC-III deficiency and apoA-I/apoC-III/apoA-IV deficiency. In contrast to the case described here, the patients with additional apoC-III deficiency have low VLDL and IDL with normal or low LDL cholesterol $(55,56)$. Both syndromes show complex abnormalities of lipoprotein metabolism, therefore the mechanisms leading to a different lipoprotein pattern from our patient remain unresolved.

There have been two other patients described with pure apoA-I deficiency $(29,57,58)$. One patient $(29,57)$ has also severely decreased apoC-III and apoC-II and no hypercholesterolemia. In fact, the initial presentation of this case was as apoAI/apoC-III deficiency (57). The reason for the decreased apoCIII in this patient has not been elucidated. The low apoC-III provides evidence for a potentially important role of apoC-III in the pathogenesis of hypercholesterolemia in apoA-I deficiency. Unfortunately, there are no detailed data about her first degree relatives available, so that the exact mode of inheritance is not known.

The genetic defect of the patient described by Gustafson et al. (58) could not be analyzed. Thus, it is not known, whether this patient is similar to the patient described here. The patient had also planar xanthomas and corneal clouding. ApoC-III was normal or even slightly elevated. Different from our proband, this patient had hypertriglyceridemia.

In the patient described here, lipoprotein determinations show two striking abnormalities: one is the lack of HDL, and the other is hypercholesterolemia. The lack of HDL is a direct consequence of the inability to synthesize apoA-I. On analytical and preparative ITP as well as fractionation by superose chromatography, it was demonstrated, that the small amount of lipoproteins in the HDL density range is mainly composed of apoE, apoA-II, and apoA-IV-containing particles. The data obtained by superose chromatography indicate that the percentage of apoA-IV, which is lipoprotein associated is only half of normal. This is probably related to the complete lack of normal HDL particles. The apoA-IV particles may account for part of the HDL cholesterol measured in the child's serum. However, the correlation may be confounded by the fact that apoA-IV particles may not be stable on ultracentrifugation.

Serum LDL is increased, whereas VLDL is low in our patient. This increase in LDL is enough to be reflected in an increased total serum cholesterol. On analytical ITP, there is an increase in the fractions corresponding to LDL (11-14), whereas the remnant fractions (8-10) are reduced. This indicates efficient conversion of remnant particles to LDL. The reason for the increased LDL-cholesterol is not entirely clear. It is not caused by a defect in the LDL receptor. In addition, it is unlikely that another genetic defect (e.g., apoB-3500) is responsible, since neither parent has an increased LDL cholesterol. There are two factors that may explain the increased LDL cholesterol. One is the lack of HDL, with a subsequent redistribution of C-apolipoproteins. Since apoC-III levels are normal in the HDL-deficient patient, one may assume that apoC-III and the other $\mathrm{C}$-apolipoproteins are predominantly associated with apoB-containing particles. C-Apolipoproteins are known to in- terfere with the uptake of remnant particles. It is believed that apoC-III inhibits binding of apoE to its specific receptor (5961 ). The reduced clearance of remnant particles could lead to an increased production rate of LDL, provided that lipolysis proceeds efficiently. As discussed above, the lack of remnant accumulation shown by analytical ITP supports this hypothesis. This is different to the situation in familial dysbetalipoproteinemia with an accumulation of $\beta$-VLDL but low LDL-cholesterol (62). Also HDL deficiency in Tangier patients is not accompanied by high LDL levels. These patients obviously cannot convert triglyceride-rich particles normally (25).

The second factor may be complete transfer of cholesteryl esters into VLDL, IDL, and LDL. This situation is opposite to CETP deficiency, where transfer of cholesterol esters from HDL to VLDL or IDL is severely impaired. Cholesterol esters accumulate in HDL. This leads to the formation of apoE rich $\mathrm{HDL}_{\mathrm{C}}$, that may be cleared by the apoB/E or the apoE receptor. Interestingly, these patients have low apoB-associated cholesterol (33). In HDL deficiency with xanthomas cholesterol efflux from peripheral cells is impaired. The plasmatic cholesterol acceptor is not known with certainty. Possibly, excess cellular cholesterol is removed by an apoA-IV/LCAT particle. This cholesterol would then have to be rapidly transferred onto triglyceride-rich particles, because the initial acceptor particles are unstable. This mechanism increases cholesterol and cholesteryl esters in remnant like particles and contributes to the increased flux into LDL.

We propose two mechanisms which may contribute to the increased LDL levels in HDL deficiency with xanthomas. First there is increased efflux of cholesteryl esters into the VLDL/ IDL density fraction. Second there is impaired removal of remnant particles with rapid conversion of these particles to LDL. The increased production of LDL may lead to downregulation of an otherwise normal LDL receptor pathway. Metabolic studies and in vitro studies with lipoproteins isolated from the HDL-deficient patient are necessary to prove this hypothesis.

The lack of HDL particles has important consequences for lipoprotein metabolism. This is similar to the other HDL deficiency syndromes. The complete lack of apoA-I permits analysis of the relative importance of apoA-I in the interaction of lipoproteins with cells. In our assay system for HDL binding to the cell surface, specific binding of HDL particles to leukocytes is reduced in the postprandial state. This is seen with postprandial leukocytes from normal probands as well as from Tangier patients. It is likely that this effect is caused by the appearance of apoA-I-rich postprandial particles with high affinity to cell surface receptors. When postprandial leukocytes from the HDL-deficient patient are used in this assay, no difference to fasting leukocytes is observed, even though apoA-IV and apoA-II increase in the postprandial phase. This is taken as evidence that apoA-I-rich postprandial particles compete for cell surface binding sites with labeled $\mathrm{HDL}_{3}$ particles.

Due to the lack of the major ligand for HDL binding, there is a defect in reverse cholesterol transport in our patient. There may still be some cholesterol uptake by the remaining apoAIV/LCAT particles and possibly by apoE/apoA-II particles. The efficacy of this process has not been analyzed so far. We have no direct evidence that there is direct uptake of free cholesterol by apoB particles with subsequent esterification within this density range.

The cardiovascular risk of the kindred presented is difficult to assess in comparison to the other HDL-deficiency syn- 
dromes. The homozygous proband is still a child and has no signs of CVD. The oldest heterozygotes alive are in their late 40 s and early 50s. They do not have symptoms of CVD. Since these people live in a remote area of Turkey, it was not possible to obtain more sophisticated cardiologic tests on them (e.g. stress tests, thallium scans, etc.). The obligate heterozygous individual II-3 died suddenly at the age of 62 . Whether this was due to CVD cannot be determined anymore. Thus, to obtain a more reliable assessment of cardiovascular risk, it will be necessary to follow this family for several years.

Metabolic studies in vivo are necessary to supplement the in vitro studies presented here. They will permit a more detailed description of the factors contributing to hypercholesterolemia in the proband. The analysis of apoB metabolism and its postprandial changes will be of particular interest.

\section{Acknowledgments}

This work was supported in part by the Deutsche Forschungsgemeinschaft within the SFB 310 "Intra-und Interzelluläre Erkennungssysteme" (G.S.) and a grant from the Austrian Fonds zur Förderung der wissenschaftlichen Forschung (S4604) to H.D.

\section{References}

1. Havel, R. J., and J. P. Kane. 1989. Structure and metabolism of plasma lipoproteins. In The Metabolic Basis of Inherited Disease. 8th edition. C. R. Scriver, A. L. Beaudet, W. S. Sly, and D. Valle, editors. McGraw-Hill, Inc., New York. 1129-1138.

2. Gordon, D., and B. M. Rifkind. 1989. High density lipoproteins: the clinical implications of recent studies. $N$. Engl. J. Med. 321:1311-1315.

3. Tall, A. R. 1990. Plasma high density lipoproteins: metabolism and relationship to atherogenesis. J. Clin. Invest. 86:379-384.

4. Castelli, W. P., R. J. Garrison, P. W. F. Wilson, R. D. Abbott, S. Kalousdian, and W. B. Kannel. 1986. Incidence of coronary heart disease and lipoprotein cholesterol levels: the Framingham Study. JAMA (J. Am. Med. Assoc.) 256:2835-2838.

5. Stampfer, M. J., F. M. Sacks, S. Salvini, W. C. Willett, and C. H. Hennekens. 1991. A prospective study of cholesterol, apolipoproteins, and the risk of myocardial infarction. $N$. Engl. J. Med. 325:373-381.

6. Badimon, J. J., L. Badimon, A. Galvez, R. Dische, and V. Fuster. 1989. High density lipoprotein plasma fractions inhibit aortic fatty streaks in cholesterol-fed rabbits. Lab. Invest. 60:455-461.

7. Badimon, J. J., L. Badimon, and V. Fuster. 1990. Regression of atherosclerotic lesions by high density lipoprotein plasma fraction in the cholesterol-fed rabbit. J. Clin. Invest. 85:1234-1241.

8. Rubin, E. M., R. M. Krauss, E. A. Spangler, J. G. Verstuyft, and S. M. Clift 1991. Inhibition of early atherogenesis in transgenic mice by human apolipoprotein AI. Nature (Lond.). 353:265-267.

9. Schmitz, G., and E. Williamson. 1991. High-density lipoprotein metabolism, reverse cholesterol transport and membrane protection. Curr. Opin. Lip idol. 2:177-189.

10. Johnson, W. J., F. H. Mahlberg, G. H. Rothblat, and M. C. Phillips. 1991 Cholesterol transport between cells and high-density lipoproteins. Biochim Biophys. Acta. 1085:273-298.

11. Gordon, J. I., H. F. Sims, S. R. Lentz, C. Edelstein, A. M. Scanu, and A. W. Strauss. 1983. Proteolytic processing of human preproapolipoprotein A-I. J. Biol. Chem. 258:4037-4044.

12. Gordon, J. I., K. A. Budelier, H. F. Sims, C. Edelstein, A. M. Scanu, and A. W. Strauss. 1983. Biosynthesis of human preproapolipoprotein A-II. J. Biol. Chem. 258:14054-14059.

13. Law, S. W., and H. B. Brewer, Jr. 1984. Nucleotide sequence and the encoded amino acids of human apolipoprotein A-I mRNA. Proc. Natl. Acad. Sci. USA. 81:66-70.

14. Seilhamer, J. J., A. A. Protter, P. Frossard, and B. Levy-Wilson. 1984. Isolation and DNA sequence of full-length cDNA and of the entire gene for human apolipoprotein AI: discovery of a new genetic polymorphism in the apoAI gene. DNA (NY). 3:309-317.

15. Protter, A. A., B. Levy-Wilson, J. Miller, G. Bencen, T. White, and J. J. Seilhamer. 1984. Isolation and sequence analysis of the human apolipoprotein CIII gene and the intergenic region between the apo $\mathrm{AI}$ and apo CIII genes. DNA (NY). 3:449-456.
16. Lackner, K. J., S. W. Law, and H. B. Brewer, Jr. 1985. The human apolipoprotein A-II gene: complete nucleic acid sequence and genomic organization. Nucleic Acids Res. 13:4597-4608.

17. Karathanasis, S. K. 1985. Apolipoprotein multigene family: Tandem organization of human apolipoprotein AI, CIII, and AIV genes. Proc. Natl. Acad. Sci. USA. 82:6374-6378.

18. Lackner, K. J., S. W. Law, H. B. Brewer, Jr., A. Y. Sakaguchi, and S. L. Naylor. 1984. The human apolipoprotein A-II gene is located on chromosome 1. Biochem. Biophys. Res. Commun. 122:877-883.

19. Middleton-Price, H. R., J. A. van den Berghe, J. Scott, T. J. Knott, and S. Malcolm. 1988. Regional chromosomal localisation of APOA2 to 1q21-1q23. Hum. Genet. 79:283-285.

20. Bisgaier, C. L., and R. M. Glickman. 1983. Intestinal synthesis, secretion and transport of lipoproteins. Annu. Rev. Physiol. 45:625-635.

21. Marsh, J. B. 1976. Apoproteins of the lipoproteins in a non recirculation perfusate of rat liver. J. Lipid Res. 17:85-90.

22. Mahley, R. W., T. L. Innerarity, S. C. Rall, Jr., and K. H. Weisgraber. 1984. Plasma lipoproteins: apolipoprotein structure and function. J. Lipid Res. 25:1277-1294.

23. Breslow, J. L. 1989. Familial disorders of high density lipoprotein metabolism. In The Metabolic Basis of Inherited Disease. 8th edition. C. R. Scriver, A. L. Beaudet, W. S. Sly, and D. Valle, editors. McGraw-Hill, Inc., New York. 12511266.

24. Schonfeld, G. 1990. The genetic dyslipoproteinemias: nosology update 1990. Atherosclerosis. 81:81-93.

25. Assmann, G., G. Schmitz, and H. B. Brewer, Jr. 1989. Familial high density lipoprotein deficiency: Tangier disease. In The Metabolic Basis of inherited disease. 8th edition. C. R. Scriver, A. L. Beaudet, W. S. Sly, and D. Valle, editors. McGraw-Hill, Inc. New York. 1267-1282.

26. Norum, R. A., E. Gjone, and J. A. Glomset. 1989. Familial Lecithin: cholesterol acytransferase deficiency, including fish eye disease. In: The metabolic basis of inherited disease. 8th edition. C. R. Scriver, A. L. Beaudet, W. S. Sly, and D. Valle, editors. McGraw-Hill, Inc., New York. 1181-1194.

27. Karathanasis, S. K., E. Ferris, and I. A. Haddad. 1987. DNA inversion within the apolipoproteins AI/CIII/AIV-encoding gene cluster of certain patients with premature atherosclerosis. Proc. Natl. Acad. Sci. USA. 84:7198-7202.

28. Ordovas, J. M., D. K. Cassidy, F. Civeira, C. L. Bisgaier, and E. J. Schaefer. 1989. Familial apolipoprotein A-I, C-III, and A-IV deficiency and premature atherosclerosis due to deletion of a gene complex on chromosome $11 . J$. Biol. Chem. 264:16339-16342.

29. Matsunaga, T., Y. Hiasa, H. Yanagi, T. Maeda, N. Hattori, K. Yamakawa, Y. Yamanouchi, I. Tanaka, T. Obara, and H. Hamaguchi. 1991. Apolipoprotein A-I deficiency due to a codon 84 nonsense mutation of the apolipoprotein A-I gene. Proc. Natl. Acad. Sci. USA. 88:2793-2797.

30. Funke, H., A. von Eckardstein, P. H. Pritchard, M. Karas, J. J. Albers, and G. Assmann. 1991. A frameshift mutation in the human apolipoprotein A-I gene causes high density lipoprotein deficiency, partial lecithin: cholesterol-acyltransferase deficiency, and corneal opacities. J. Clin. Invest. 87:371-376.

31. Deeb, S. S., K. Takata, R. L. Peng, G. Kajiyama, and J. J. Albers. 1990. A splice-junction mutation responsible for familial apolipoprotein A-II deficiency. Am. J. Hum. Genet. 46:822-827.

32. Brown, M. L., A. Inazu, C. B. Hesler, L. B. Agellon, C. Mann, M. E. Whitlock, Y. L. Marcel, R. W. Milne, J. Koizumi, H. Mabuchi, et al. 1989. Molecular basis of lipid transfer protein deficiency in a family with increased high-density lipoproteins Nature (Lond.). 342:448-451.

33. Yamashita, S., D. L. Sprecher, N. Sakai, Y. Matsuzawa, S. Tarui, and D. Y. Hui. 1990. Accumulation of apolipoprotein E-rich high density lipoproteins in hyperalphalipoproteinemic human subjects with plasma cholesteryl ester transfer protein deficiency. J. Clin. Invest. 86:688-695.

34. Jeenah, M., A. Kessling, N. Miller, and S. Humphries. 1990. G to A substitution in the promoter region of the apolipoprotein AI gene is associated with elevated serum apolipoprotein AI and high density lipoprotein cholesterol. Mol. Biol. Med. 7:233-241.

35. Goldberg, I. J., W. S. Blaner, T. M. Vanni, M. Moukides, and R. Ramakrishnan. 1990. Role of lipoprotein lipase in the regulation of high density lipoprotein apolipoprotein metabolism. J. Clin. Invest. 86:463-473.

36. Clay, M. A., K. A. Rye, and P. J. Barter. 1990. Evidence in vitro that hepatic lipase reduces the concentration of apolipoprotein A-I in rabbit high density lipoproteins. Biochim. Biophys. Acta. 1044:50-56.

37. Schmitz, G., G. Assmann, B. Brennhausen, and H.-J. Schaefer. 1987 Interaction of tangier lipoproteins with cholesteryl ester-laden mouse peritoneal macrophages. J. Lipid Res. 28:87-99.

38. Chirgwin, J. M., A. E. Przybyla, R. J. MacDonald, and W. J. Rutter. 1979. Isolation of biologically active ribonucleic acid from sources enriched in ribonuclease. Biochemistry 18:5294-5298.

39. Sambrook, J., E. F. Fritsch, and T. Maniatis. 1989. Molecular Cloning: A Laboratory Manual. Cold Spring Harbor Laboratory Press, Cold Spring Harbor, NY.

40. Frischauf, A.-M., H. Lehrach, A. Poustka, and N. Murray. 1983. Lambda replacement vectors carrying polylinker sequences. J. Mol. Biol. 170:827-842. 
41. Sanger, F., Nicklen, S., and A. R. Coulson. 1977. DNA sequencing with chain terminating inhibitors. Proc. Natl. Acad. Sci. USA. 74:5463-5466.

42. Kidd, V. J., R. B. Wallace, K. Itakura, and S. L. C. Woo. 1983. $\alpha 1$-Antitrypsin deficiency detection by direct analysis of the mutation in the gene. Nature (Lond.). 304:230-234.

43. Dieplinger, H., E.-M. Lobentanz, P. König, H. Graf, C. Sandholzer, E. Matthys, M. Rosseneu, and G. Utermann. 1992. Plasma apolipoprotein A-IV metabolism in patients with chronic renal disease. Eur. J. Clin. Invest. 22:166174.

44. Nowicka, G., T. Brüning, A. Böttcher, G. Kahl, and G. Schmitz. 1990. Macrophage interaction of HDL subclasses separated by free flow isotachophoresis. J. Lipid Res. 31:1947-1963.

45. Nowicka, G., T. Brüning, B. Grothaus, G. Kahl, and G. Schmitz. 1990. Characterization of apolipoprotein B-containing lipoproteins separated by preparative free flow isotachophoresis. J. Lipid Res. 31:1173-1186.

46. Steyrer, E., and G. M. Kostner. 1988. Activation of lecithin-cholesterol acyltransferase by apolipoprotein $\mathrm{D}$ : comparison of proteoliposomes containing apolipoprotein D, A-I, or C-I. Biochim. Biophys. Acta. 958:484-491.

47. Schmitz, G., G. Wulf, T. Brüning, and G. Assmann. 1987. Flow-cytometric determination of high-density-lipoprotein binding sites on human leukocytes. Clin. Chem. 33:2195-2203.

48. Schmitz, G., R. Niemann, B. Brennhausen, R. Krause, and G. Assmann. 1985. Regulation of high density lipoprotein receptors in cultured macrophages: role of acyl-CoA: cholesterol acyltransferase. EMBO (Eur. Mol. Biol. Organ.) J. 11:2773-2779.

49. Schmitz, G., T. Brüning, E. Kovacs, and S. Barlage. 1993. Fluorescence flow cytometry of human leukocytes in the detection of LDL-receptor defects in the differential diagnosis of hypercholesterolemia. Arterioscler. Thromb. 13: 1053-1065.

50. Brown, M. S., and J. L. Goldstein. 1979. Receptor-mediated endocytosis insights from the lipoprotein receptor system. Proc. Natl. Acad. Sci. USA 76:3330-3337.

51. Antonarakis, S. E., P. Oettgen, A. Chakravarti, S. L. Halloran, R. R. Hudson, L. Feisee, and S. K. Karathanasis. 1988. DNA polymorphism haplotypes of the human apolipoprotein APOA1-APOC3-APOA4 gene cluster. Hum. Genet. 80:265-273.

52. De-Bruin, T. W., C. B. Brouwer, J. A. Gimpel, and D. W. Erkelens. 1991.
Postprandial decrease of HDL apo A-I in normal subjects in relation to triglyceride metabolism. Am. J. Physiol. 260:E492-498.

53. Seishima, M., A. Noma, H. Torizawa, and Y. Muto. 1988. Changes of serum apolipoprotein levels after oral administration of fat in human subjects. Atherosclerosis. 73:39-43.

54. Karathanasis, S. K., V. I. Zannis, and J. L. Breslow. 1983. Isolation and characterization of the human apolipoprotein A-I gene. Proc. Natl. Acad. Sci. USA. 80:6147-6151.

55. Norum, R. A., J. B. Lakier, S. Goldstein, A. Angel, R. B. Goldberg, W. D. Block, D. K. Noffze, P. J. Dolphin, J. Edelglass, D. D. Bogorad, et al. 1982. Familial deficiency of apolipoproteins A-I and C-III and precocious coronary-artery disease. N. Engl. J. Med. 306:1513-1519.

56. Schaefer, E. J., W. H. Heaton, M. G. Wetzel, and H. B. Brewer, Jr. 1982. Plasma apolipoprotein A-I absence associated with a marked reduction of high density lipoproteins and premature coronary artery disease. Arteriosclerosis. 2:16-26.

57. Hiasa, Y., T. Maeda, and H. Mori. 1986. Deficiency of apolipoproteins A-I and C-III and severe coronary heart disease. Clin. Cardiol. 9:349-352.

58. Gustafson, A., W. J. McConathy, P. Alaupovic, M. D. Curry, and B. Persson. 1979. Identification of lipoprotein families in a variant of human plasma apolipoprotein A deficiency. Scand. J. Clin. Lab. Invest. 39:377-387.

59. Windler, E., and R. J. Havel. 1985. Inhibitory effects of C apolipoproteins from rats and humans on the hepatic uptake of triglyceride-rich lipoproteins and their remnants by the liver. J. Lipid Res. 26:557-565.

60. Ito, Y., N. Arzolan, A. O'Connell, A. Walsh, and J. L. Breslow. 1990. Hypertriglyceridemia as a result of human apo CIII gene expression in transgenic mice. Science (Wash. DC). 249:790-793.

61. Weisgraber, K. H., R. W. Mahley, R. C. Kowal, J. Herz, J. L. Goldstein, and M. S. Brown. 1990. Apolipoprotein C-I modulates the interaction of apolipoprotein $\mathrm{E}$ with beta-migrating very low density lipoproteins (beta-VLDL) and inhibits binding of beta-VLDL to low density lipoprotein receptor-related protein. J. Biol. Chem. 265:22453-22459.

62. Mahley, R. W., and S. C. Rall, Jr. 1989. Type III hyperlipoproteinemia (Dysbetalipoproteinemia): The role of apolipoprotein $\mathrm{E}$ in normal and abnormal lipoprotein metabolism. In The Metabolic Basis of Inherited disease. 8th edition. C. R. Scriver, A. L. Beaudet, W. S. Sly, and D. Valle, editors. McGraw-Hill, Inc. New York. 1195-1213. 